\title{
POLÍTICAS EDUCACIONAIS: GESTÃO DOS IMPASSES DO ENSINO- APRENDIZAGEM NA PERSPECTIVA DE DOCENTES E DISCENTES DA EJA
}

\author{
EDUCATIONAL POLICIES : MANAGEMENT OF TEACHING-LEARNING \\ IMPASSES FROM THE PERSPECTIVE OF TEACHERS AND STUDENTS OF EJA
}

\author{
POLÍTICAS EDUCATIVAS: GESTIÓN DE LOS APRENDIZAJES DE \\ APRENDIZAJE EN LA PERSPECTIVA DE LOS ESTUDIANTES DOCENTES DE \\ EJA
}

\section{Ruan Carlos dos Santos}

Titulação: Mestre em Administração

Instituição: Centro Universitário UNIAVAN/Professor Curso de Tecnologia de Gestão Financeira

SED-SC/ Professor de Filosofia e Sociologia no EJA

UNIVALI/ Doutorando no Programa de Pós-graduação em Administração

UNIASSELVI/Professor na Especialização de Gestão Escolar e Orientação Pedagógica

E-mail: ruan.santos@ uniavan.edu.br

Orcid: http://orcid.org/0000-0001-7396-8774

\section{Katia Santos}

Titulação: Especialista em Gestão Escolar Instituição: SED-SC/ Professora de Ciências Sociais e Biologia

SED-SC/ Coordenadora das UD's do Vale do Itajaí

SME-TIJUCAS-SC/ Professora de Biologia

E-mail: katiabio.tijucas@ hotmail.com

Orcid: https://orcid.org/0000-0001-8254-7330

\begin{abstract}
RESUMO
Esta pesquisa, que busca aprofundar os estudos sobre a Educação de Jovens e Adultos (EJA), tem como objetivo geral identificar os principais impasses e desafios vivenciados pelos professores dessa modalidade de educação em um contexto educativo. Em termos metodológicos, esta pesquisa é de natureza qualitativa, tendo como modalidade principal o estudo de caso e, como modalidades secundárias, a pesquisa documental, que propiciou a análise do Projeto Político-pedagógico, Regimento Escolar e Plano Curricular, bem como a bibliográfica, constituída a partir da leitura de artigos e teses sobre o assunto; a de campo, que comportou o uso de entrevistas estruturadas destinadas aos docentes e questionários direcionados aos discentes, com observação participante. A pesquisa foi realizada de abril de 2018 a fevereiro de 2019 nas Unidades Descentralizadas (UD's) do Vale do Rio Tijucas da Secretaria Estadual de Educação de Santa Catarina que atende o Ensino Fundamental ( $5^{\circ}$ ao $9^{\circ}$ ano) e o Ensino Médio ( $1^{\circ}$ ao $3^{\circ}$ ano) da EJA nos três turnos do dia. Os resultados indicam que há déficit na capacitação docente; falta de material didático específico para os alunos da EJA; evasão de alunos e necessidade de adaptar os documentos norteadores do trabalho pedagógico às especificidades do público atendido. Conclui-se que a gestão da Educação de Jovens e Adultos necessita de maior atenção no que tange às questões básicas da educação, exige a efetivação da gestão democrática e metodologia de ensino diferenciada, para garantir melhor qualidade de ensino da Educação de Jovens e Adultos.
\end{abstract}

Palavras-chave: Educação de Jovens e Adultos. Impasses. Desafios. Gestão escolar. 


\begin{abstract}
Aiming to deepen the body of knowledge on Youth and Adult Education, this study has as its general objective to identify the main impasses and challenges experienced by teachers of this modality of education. As its specific objectives, it seeks to understand the specificities of EJA from documentary research, learn more about the subjects' profile (teachers and students) and identify aspects of pedagogical practice that need intervention. In order to reach its objectives, this qualitative study adopted different research methods and instruments, namely case study, documentary, bibliographic and field research as well as participant observation and application of questionnaires and interviews with the participants. Results show that there is lack of teacher development, lack of specific didactic material for EJA students in addition to student dropouts and the need to adapt the guiding documents of the pedagogic work to the specificities of the target audience. It is possible to conclude that the management of Youth and Adult Education requires not only greater attention regarding the basic issues of education but also the effective management of democracy and differentiated teaching methodology so as to ensure better quality of education for this modality of education.
\end{abstract}

Keywords: Youth and Adult Education. Impasses. Challenges. School management.

\title{
RESUMEN
}

Esta investigación busca profundizar los estudios sobre la Educación de Jóvenes y Adultos (EJA), teniendo como objetivo general identificar los principales impasses y desafíos experimentados por los docentes de este tipo de educación en un contexto educativo. En términos metodológicos, esta investigación es de naturaleza cualitativa, teniendo como modalidad principal el estudio de caso y como modalidades secundarias para: la investigación documental, que proporcionó el análisis del Proyecto Político Pedagógico, el Regimiento Escolar y el Plan Curricular, el bibliográfico, constituido a partir de leer artículos y tesis sobre el tema; el campo, que incluyó el uso de entrevistas estructuradas para maestros y cuestionarios dirigidos a estudiantes; con observación participante La encuesta se realizó entre abril de 2018 y febrero de 2019 en Unidades Descentralizadas (UD's) de Tijucas River Valley del Departamento de Educación del Estado de Santa Catarina, que atiende desde la escuela primaria $\left(5^{\circ}\right.$ a $9^{\circ}$ grado) y la escuela secundaria $\left(1^{\circ}\right.$ a $3^{\circ}$ grado) de la EJA. Tres turnos del día (mañana, tarde y noche). Los resultados indican que hay un déficit en la formación del profesorado; falta de material didáctico específico para estudiantes de EJA; la deserción de estudiantes y la necesidad de adaptar los documentos guía del trabajo pedagógico a las especificidades del público servido. Se concluye que la gestión de la educación de jóvenes y adultos necesita mayor atención con respecto a los temas básicos de la educación, requiere la implementación de una gestión democrática y una metodología de enseñanza diferenciada, para garantizar una mejor calidad de la educación de jóvenes y adultos.

Palabras clave: Educación de jóvenes y adultos. Impasse. Desafíos. Gestión escolar.

\section{INTRODUÇÃO}

Na contemporaneidade, verifica-se que as finalidades da educação, pela sua dimensão social e política, ultrapassam os raios de atuação da escola. Assim, no que concerne à Educação de Jovens e Adultos (EJA), não se pode perder de vista a sua especificidade. Essa modalidade de ensino pode ser considerada como o canal que abre a possibilidade para compreender a implementação de políticas educacionais, seus processos, dificuldades e condições possíveis de materialização da aprendizagem institucionalizada. 


\section{Seção: Gestão - Artigo original}

À luz do exposto, esta temática foi escolhida em virtude do desejo e da necessidade de aprofundar os estudos sobre a EJA para melhor compreendê-la e, por isso, estão interligados à impetuosa evolução científica e tecnológica, refletindo na forma de ser e de viver em sociedade, afetando o papel da escola no processo de formar cidadãos. Assim, ao pensar sobre a EJA, nesse contexto, deparamo-nos com a dificuldade de interligar esta modalidade aos diversos fatores da sociedade, principalmente aos que dizem respeito à formação humana. A oferta dessa modalidade de ensino continua desassistida e insuficientemente financiada.

A prática pedagógica e a organização do sistema escolar brasileiro, em relação à EJA, ainda são instituídas por uma visão assistencialista e compensatória, marcada pela descontinuidade das políticas públicas e pelo descaso com as especificidades das ações educativas neste campo de ensino. Em outras palavras, a educação de jovens e adultos, nos seus diversos espaços formais de ensino, ainda se desenvolve na perspectiva da "reparação da escolaridade perdida", evidenciando lacunas em muitas escolas brasileiras no tocante às questões administrativas, pedagógicas e financeiras. Relativamente aos três pilares citados anteriormente, a figura do gestor escolar é vislumbrada como capaz de intermediar os diversos desafios e construir possibilidades para uma educação de qualidade, dentro do contexto escolar.

Diante desse contexto, Begot e Nascimento (2002) afirmam que o gestor escolar precisa estar antenado às suas nuances profissionais, de forma a entender que a comunidade escolar e extraescolar esperam muito de sua atuação. Bittar e Oliveira (2004) despontam que um gestor escolar contemporâneo deve preocupar-se com aspectos que extrapolam o administrativo e o pedagógico, ou seja, com o social. Assim, é importante estar comprometido com sua atuação enquanto possibilidade de articulação e modificação de realidades humanas. Ao relatar esse aspecto social, percebe-se a importância de uma gestão escolar pautada na escuta e aberta às discussões com seus pares. Ao adentrar essa discussão, é relevante destacar a importância da gestão democrática na organização escolar. Sendo assim, a gestão escolar só irá estabelecer seu papel pautada na política da dialogicidade, exercendo e fazendo exercer a confiança na multiplicidade dos sujeitos que sustentam o cenário escolar.

Luck (2000) desponta que o termo "gestão escolar" carrega um significado muito maior que apenas a administração escolar; a gestão deve, em si, promover possibilidades educacionais que irão desembocar na melhoria da oferta e qualidade do ensino. Ademais, a autora evidencia que a perspectiva gestora deve constituir-se como um meio, e não um fim para as possibilidades de aprendizagem dos alunos. Ainda é importante expor a importância do ambiente escolar, que é constituído pela gestão, e as possibilidades de desenvolvimentos de competências e atitudes. Nessa linha de pensamento, Luck (2008) suscita a discussão de que a 
ação do gestor será engessada se sua concepção dos processos educativos for limitada, daí a importância da liderança e do aspecto democrático do gestor.

Nesse sentido, é importante destacar a função da gestão escolar na educação básica e, especificamente, na modalidade da Educação de Jovens e Adultos, que é um campo muitas vezes estereotipado e acaba por não receber o mesmo tratamento de outras modalidades. A EJA comumente é enxergada pela maioria dos gestores escolares como uma escola que está à parte, o que acaba por suprimir as especificidades dos sujeitos que são portadores e produtores de saberes.

Reforçando essa ideia, Amorim (2012) salienta que a educação de qualidade, o próprio acesso ao ensino e permanência nele extrapola o prescrito nas políticas públicas e acaba por envolver os gestores, professores, técnicos e toda a equipe escolar. Assim, para compreender melhor as condições de oferta desta modalidade de ensino, o estudo se desenvolve pela seguinte questão: como tem sido o processo de gestão escolar da EJA nas Unidades Descentralizadas (UD's) do Vale do Rio Tijucas, em relação às políticas educacionais?

Nesse intuito, o objetivo geral deste estudo é identificar os principais impasses e desafios vivenciados pelos discentes e docentes da EJA no Centro Educacional do Núcleo Avançado de Ensino Supletivo (NAES) em Tijucas, buscando identificar reflexivamente os avanços alcançados por tal modalidade de ensino e as dificuldades enfrentadas nesse processo.

Após as ponderações já mencionadas, que constituem a introdução deste artigo (1), apresenta-se, na sequência, na segunda seção, o referencial teórico da pesquisa tomando por base os estudos de Cavaco (1992), Nóvoa (1995), Giroux (1997), Barone (2000), Machado (2000), Contreras (2002), Moll (2004), Soares, Giovanetti e Gomes (2005), Arroio (2005); Tardif (2005); Leão (2007), Oliveira (2007), Meyer (2008), Barcelos (2010), Arroyo (2012) e Luck (2014); já na Metodologia (3), apresenta-se a abordagem, as modalidades de pesquisa, os procedimentos e os instrumentos utilizados para a organização dos dados em estudo; e, por fim, na seção "Descrição e análise dos dados" (4), são apresentados os resultados e a análise desses dados com base no referencial teórico, findando-se com as considerações finais acerca da pesquisa.

\section{REFERENCIAL TEÓRICO}

Apresentamos, na sequência, as bases conceituais desta investigação, tratando da gestão escolar e o que isso implica em relação à qualidade da EJA, bem como sobre as dificuldades dos professores que trabalham nessa modalidade de educação. 


\subsection{GESTÃO ESCOLAR E SUA IMPLICAÇÃO COM A QUALIDADE DA ESCOLARIZAÇÃO DA EJA}

A definição do termo "gestão escolar" consiste no mecanismo de orientação e de mobilização dos diversos sujeitos presentes na escola, além da promoção da organização de procedimentos e de recursos, de forma que facilite a efetivação do papel social da escola por meio de seus objetivos educacionais, proporcionando aprendizagens significativas e formação de sujeitos críticos. O termo 'gestão escolar' tem sua constituição e utilização crescente com a promulgação da Constituição Federal de 1988, especificamente no artigo 206, que disserta sobre a: “[...] gestão democrática do ensino público, na forma da lei [...]” (BRASIL, 1996). Além disso, a Lei de Diretrizes e Bases da Educação Nacional nº. 9394/96, no seu artigo 14, determina o preceito da gestão democrática como sendo um dos seus princípios, pressupondo a gestão democrática como um trabalho grupal, dinâmico e dialógico.

Nessa mesma perspectiva, Luck (2008) evidencia que o conceito de gestão escolar resulta de um novo entendimento que está relacionado com os caminhos das instituições como um todo, além de levar em consideração seus pares, promovendo de tal forma uma maior articulação. A gestão educacional expressa, dessa forma, a superação do conceito forjado dos processos administrativos, na perspectiva da mudança de visão de mundo e dos processos reais que o ambiente escolar vivencia na contemporaneidade.

No entendimento de Kuhn (1982), suscita ainda mais esta mudança de paradigma necessária e urgente na contemporaneidade. Além disso,

\footnotetext{
[...] a mudança do enfoque de administração para o de gestão, que vem ocorrendo no contexto das organizações e dos sistemas de ensino, como parte de um esforço fundamental para a mobilização, organização e articulação do desempenho humano e promoção da sinergia coletiva, em seu contexto, voltados para o esforço competente de promoção da melhoria do ensino brasileiro e sua evolução (LUCK, 2014, p. 34$35)$.
}

Diante do exposto, a autora redimensiona a gestão na educação como possibilidade de estabelecimento de práticas interativas, participativas, de cunho democrático, que sejam caracterizadas por movimentos dinâmicos, uma vez que todos os pares buscam a superação de emblemas que afetam direta e indiretamente a realidade da escola, a qual, enquanto instituição social, está sujeita a processos de mudanças para acompanhar as condições externas proporcionadas pela contemporaneidade.

Diante disso, as concepções de gestão apresentadas até aqui podem criar meios de aproximação com as respostas para os problemas e impasses da EJA. Pensar a gestão escolar, hoje, como uma mudança de paradigma abre possibilidades para a melhoria do processo de escolarização da EJA, implicando a garantia de uma educação igualitária e justa, capaz de 
reconhecer a importância do trabalho participativo e democrático. Dessa forma, quando a gestão escolar de EJA pautar-se nesse princípio participativo e coletivo, criará condições para o reconhecimento da modalidade.

Entendemos que, em relação à formação histórica e social da Educação de Jovens e Adultos no Brasil, torna-se necessário refletir sobre o processo de gestão escolar nessa modalidade, conforme suas especificidades, impasses e perspectivas educacionais. Por isso, para Lima, Silva e Santos (2015, p. 80), “[...] a gestão educacional para a escola de jovens e adultos precisa considerar na organização, a historicidade dessa modalidade de ensino e constante processo de formação/escolarização e aprendizagem ao longo da vida."

Observa-se que as escolas que ofertam a EJA se desenrolam por meio de impasses e ocorrências insatisfatórias que ainda revelam um processo educacional carente, o qual não tem atendido às necessidades básicas de aprendizagem dos(as) estudantes jovens e adultos(as). Com isso, percebe-se que, no cenário pedagógico da EJA, depara-se, ainda, com a falta de conhecimento sistemático e do parâmetro de qualidade nas turmas de EJA para auxiliar o planejamento e a prática pedagógica do professor; a carência de integração entre teoria e prática; a fragmentação do saber no momento da difusão do conhecimento; a descontextualização do conhecimento frente aos anseios do público-alvo; a transmissão conservadora do conhecimento, fundamentada numa "educação bancária"; práticas avaliativas conservadoras que engessam o processo de aprendizagem significativa na EJA; a necessidade de práticas escolares que respeitem as características de flexibilidade e da diversidade cultural dentro da EJA.

Outro impasse na gestão da EJA refere-se às questões administrativas. É comum nesse processo deparar-se com a falta de planejamento do gestor escolar para desenvolver ações relacionadas à: organização/estruturação dos espaços escolares (biblioteca, salas de aula, refeitório etc.); formação continuada e práticas pedagógicas de professores; implementação do projeto político-pedagógico e seu plano ação correspondente à EJA; articulação com os vários órgãos da administração pública e setores da sociedade para permanência e êxito dos jovens e adultos na escola; criação de espaço democrático e participativo para sugestão, monitoramento e avaliação coletiva das propostas didático-pedagógicas da EJA; dentre outras. Por outro lado, para Amorim (2012), essas dificuldades podem ser superadas a partir do momento em que a escola reconhecer a importância da gestão participativa em seu processo. Conforme esse autor, a participação e a construção democrática no ambiente educacional fazem com que o processo de escolarização adquira autonomia e valorize o espaço de aprendizagem, sendo reconhecido enquanto lugar de democracia e de vivência coletiva. 
Seção: Gestão - Artigo original

Considerando os problemas de ordem financeira e de infraestrutura, podem-se incluir aqueles relacionados à falta de equipamentos e de recursos didático-pedagógicos para o desenvolvimento de aulas teóricas e práticas, de salas de aula do período noturno com iluminação inadequada e sem outras condições mínimas de funcionamento e de investimentos no que se refere aos aspectos de alimentação e transporte escolar.

Diante desse levantamento, torna-se relevante reconhecer que o processo de escolarização da EJA, por meio de sua gestão participativa e democrática, precisa refletir sobre uma nova maneira de fazer e refazer a escola da EJA. Diante da posição e vivências dos grupos populares, em contexto de exclusão social e educacional, a gestão escolar necessita incluir planos de ação que aproximem a escola à realidade objetiva dos jovens e adultos estudantes dessa modalidade. E isso acaba sendo uma condição urgente e necessária, pois a maioria desse público-alvo, diante da posição que ocupa na sociedade e no contexto político/econômico, já sabe lidar com as resistências das políticas públicas local, regional e nacional, capazes de buscar o reconhecimento da sua própria identidade, enquanto pessoas trabalhadoras em diferentes situações da vida.

Entendemos que a gestão escolar deve preocupar-se com a valorização da escola pública e a qualidade dos processos educativos nos quais estão inseridos estudantes jovens e adultos. Assim, a perspectiva da melhoria da prática de gestão educacional será satisfatória a partir do momento em que o espaço escolar buscar reconhecer a superação de sua visão assistencialista e preconceituosa em relação ao (à) estudante da EJA, principalmente do turno noturno. (ARROYO, 2012). Dessa forma, quebramos rótulos e formatos da escolarização, porém, assim, buscamos amenizar (e acabar com) a condição de inexistência, subcidadania e sub-humanidade com que os estudantes do EJA foram classificados, tornando a história da produção das desigualdades sociais, raciais, étnicas, sexuais inseparáveis dessa radicalidade discriminatória.

\subsection{DIFICULDADES DOS PROFESSORES DA EJA E PROPOSTAS DE POSSÍVEIS SOLUÇÕES}

A educação de jovens e adultos no nosso país tem evoluído, porém ainda enfrenta muitas dificuldades. Dentre elas, destacam-se questões relativas ao processo de planejamento e gestão do ensino; à falta de: recursos didáticos, formação continuada dos professores, relação entre teoria e prática, articulação e aplicação de um currículo adequado; também à insegurança demonstrada por grande parte dos alunos quando retornam à escola; às dificuldades na compreensão e domínio da leitura e escrita, no saber matemático, em questões relativas à natureza e sociedade; na pertinência das avaliações aplicadas; e nas questões de gênero. 
Seção: Gestão - Artigo original

Assim, abordamos primeiramente problemas relacionados ao processo de planejamento de ensino da EJA; em alguns casos, os professores desconsideram a faixa etária e o perfil de seus alunos, não adequando as práticas ou não considerando a individualidade discente. De um planejamento inadequado, decorrem consequências desastrosas. O planejamento deve ser um processo de decisão que norteia a ação educativa, sendo que " no caso da educação de jovens e adultos, o planejamento precisa levar em conta as exigências do contexto social no qual estão inseridas, as características de cada grupo, suas aspirações, projetos e necessidades" (CALHÁU, 1999, p. 53).

O objetivo do planejamento visa a uma aprendizagem efetiva e significativa, trabalhando a favor da permanência do aluno no sistema educacional com uma avaliação crítica sobre a atuação do professor. Diante das diferenças encontradas na sala de aula, o educador não deve apenas ser um simples executor de tarefas, com foco apenas nos conteúdos, mas sim atuar de forma reflexiva. Isso porque "a noção de professor reflexivo baseia-se na consciência da capacidade de pensamento e reflexão que caracteriza o ser humano como criativo e não como mero reprodutor de ideias e práticas que lhe são exteriores" (ALARCÃO, 2004, p. 41).

Isso significa dizer que o professor reflexivo é aquele que reflete sobre sua atuação em sala de aula, construindo conhecimento a partir da sua prática pedagógica, estando aberto a mudanças e trabalhando com dedicação e comprometimento com seus alunos, para o desenvolvimento de suas aprendizagens. Conforme Fuck (1993, p. 92), deve "acreditar na capacidade de aprender de cada um, que constitui fator preponderante para o resgate da autoconfiança, indispensável na aprendizagem”.

Por essa razão, é necessário compreender que o espaço pedagógico é um lugar de constante reflexão entre as relações estabelecidas entre professor/aluno, "nesse sentido, quanto mais solidariedade exista entre o educador e o educando no 'trato' deste espaço, tanto mais possibilidades de aprendizagem democrática se abrem na escola.” (FREIRE, 1996, p. 97). Outro entrave na educação de jovens e adultos está relacionado à compreensão e domínio da leitura e escrita. As dificuldades, nesse processo, podem ocasionar um comprometimento nas outras áreas do saber, de modo que a alfabetização propicia condições para que o indivíduo tenha acesso ao mundo da escrita, fazendo uso dela em todas as funções que ela tem na sociedade.

O professor, ao proporcionar diferentes oportunidades de discussão em sala de aula, contribui favoravelmente para a formação do aluno, já que a temática gênero é integradora de vários temas transversais e faz com que o aluno se perceba como parte integrante da sociedade e agente de transformação social. Frente as dificuldades que existem na educação de jovens e adultos, o docente da EJA pode atuar de diferentes formas, com o objetivo de sanar as 
dificuldades e entraves decorrentes do processo de ensino e oferecer oportunidades de permanência de estudos aos seus discentes.

\section{METODOLOGIA DA PESQUISA}

O aporte metodológico utilizado para desenvolvimento deste estudo se baseou numa abordagem qualitativa, porque entendemos que esta estabelece uma interdependência entre o sujeito e o objeto pesquisado, direcionando para um processo reflexivo acerca do cenário social. Nesse sentido, Minayo (2006) infere que a pesquisa qualitativa versa sobre o trabalho com o universo de aspirações, significados, crenças, atitudes, procurando o espaço mais profundo dos fenômenos a serem estudados.

Além disso, segundo as orientações disseminadas por Goldenberg (1999), os pesquisadores que adotam em seus estudos a abordagem qualitativa se opõem à utilização de um único modelo de pesquisa, além de indicarem que, para cada tipo de estudo, existe uma especificidade. Nessa linha de pensamento, expõe que os pesquisadores envolvidos no desenvolvimento da investigação com essa abordagem se opõem ao modelo positivista, que se preocupa com o não julgamento e visões acerca do pesquisado. Em conformidade com isso, Gatti (2012) aponta que a pesquisa de abordagem qualitativa possibilita desbravar caminhos para superar os modelos positivistas de pesquisa, dando condições para compreender densamente os fenômenos educativos vigentes.

Em relação às modalidades de pesquisa, enfoca-se como modalidade principal o estudo de caso, pois se busca compreender aspectos de um espaço educativo em especial. Quanto às modalidades secundárias, assume-se: a) pesquisa documental, que propiciou a análise dos documentos: Projeto Político-pedagógico, Regimento Escolar e Plano Curricular; b) bibliográfica, constituída a partir da leitura de artigos e teses sobre a EJA; c) pesquisa de campo, que, segundo Gil (2008), procura o aprofundamento de uma realidade específica, sendo que, nesta investigação, houve uso de entrevistas estruturadas destinadas aos docentes e de questionários, direcionados aos discentes matriculados na EJA. Ainda em relação às modalidades secundárias, quanto aos objetivos, esta pesquisa se caracteriza também como exploratória, já que para Gil (1999), a pesquisa exploratória tem a finalidade de descrever, esclarecer e modificar conceitos e ideias a respeito de determinado tema.

Em relação aos procedimentos metodológicos, aponta-se que a pesquisa ocorreu no período de aproximadamente doze meses, entre março de 2018 a março de 2019, em uma instituição de ensino da rede pública estadual, localizada no Vale do Rio Tijucas que atende ao Ensino Fundamental ( $1^{\circ}$ ao $9^{\circ}$ ano) e ao Ensino Médio EJA. A pesquisa contou com a participação efetiva de 175 alunos (discentes), 40 docentes (professores) e 6 alunos (discentes) 
(em conversas informais) do Centro Educacional de Tijucas, tendo como intenção coletar informações sobre variáveis que afetam o desenvolvimento da gestão escolar da EJA e o processo de escolarização na instituição.

O principal instrumento de pesquisa utilizado para a organização dos dados foi a entrevista semiestruturada. Triviños (1987) expõe que esse tipo de dispositivo tem como característica questionamentos que são apoiados em hipóteses que serviram de base para o problema do estudo. Dessa forma, as entrevistas semiestruturadas proporcionam a explicação e compreensão de um fenômeno social, promovendo, assim, a presença consciente do pesquisador no processo de coleta de dados. Em conformidade com as discussões anteriores, Lüdke e André (1986) acrescentam que as entrevistas servem tanto de instrumento como também de objeto para análise de dados que não foram verbalizados, possibilitando que o pesquisador possa analisar as visões do sujeito da pesquisa. Nesta pesquisa, a entrevista continha cinco questões referentes à gestão educacional na Educação de Jovens e Adultos em Tijucas e foi aplicada aos discentes. Além desses aspectos, as entrevistas também serviram para entender o perfil e postura dos 40 docentes, as quais foram realizadas nos dias 16 e 18 abril, 22 a 25 agosto, sendo finalizadas entre os dias 7 e 10 no mês de novembro de 2018.

Além desses instrumentos, foi utilizada a observação participante, a qual ocorre por meio da observação direta do grupo estudado. Também foram realizadas conversas informais com seis alunos matriculados na $1^{\mathrm{a}}$ série da EJA, os quais se dispuseram a responder algumas perguntas.

Os colaboradores foram informados sobre o objetivo do estudo e, posteriormente, convidados a assinar o Termo de Consentimento Livre e Esclarecido. As informações obtidas foram transcritas em sua integralidade, preservando o anonimato dos sujeitos colaboradores. $\mathrm{O}$ tratamento das informações foi feito a partir de uma análise qualitativa, e, nesse sentido, esse processo é relativamente recente e vem caracterizando-se por ser um mecanismo indutivo, tendo como pressuposto o cotidiano dos sujeitos sociais, fazendo-se valer pelas mesmas características da pesquisa qualitativa. Para Fernandes (1991), a análise qualitativa se caracteriza pela busca dos significados e sentidos de informações que são mensuravelmente valiosas. Para Flick (2009), as pesquisas que têm abordagem qualitativa podem recorrer a diversos meios de análises de dados. Assim, segundo os postulados de Denzin e Lincoln (2006), os pesquisadores que optam por uma abordagem qualitativa estão livres para fazer uso da análise do discurso, de conteúdo, arquivos, fonética, tabelas, gráficos, e dados estatísticos de forma geral. 


\section{DESCRIÇÃO E ANÁLISE DOS RESULTADOS}

As informações oriundas do campo de pesquisa evidenciam uma riqueza de informações que estão presentes no desenvolvimento da gestão na Educação de Jovens e Adultos no Centro Educacional de Tijucas. Inicialmente, os dezenove colaboradores da pesquisa foram suscitados a expor sua concepção de gestão de EJA.

Os sujeitos da pesquisa foram convidados a refletir sobre em qual percepção está fundamentada a EJA; desvelando as informações da pesquisa, setenta cinco dos entrevistados demarcaram que a percepção da EJA busca igualdade de condições para todos; quarenta entrevistados expuseram que a percepção da EJA facilita o acesso e permanência na escola; apenas vinte assinalaram que a percepção da EJA preza pela qualidade; cinquenta sujeitos demarcaram que a EJA está baseada em todas as questões anteriores; e apenas cinco entrevistados assinalaram que nenhuma das alternativas anteriores está presente na percepção EJA das UD's.

Os cento e setenta e cinco discentes da pesquisa foram indagados sobre quais aspectos relativos à EJA devem ser geridos para garantir a qualidade da educação. Os direcionamentos foram diversificados, porém expõem a necessidade específica da EJA no Centro Educacional de Tanhaçu. Os aspectos que necessitam ser geridos com maior atenção expostos através da coletividade de sujeitos são: recursos pedagógicos, assiduidade e pontualidade no transporte escolar, o combate à evasão, a luta pela permanência dos alunos, acompanhamento das relações de ensino e aprendizagem, a falta de interesse e responsabilidade dos alunos, melhoria do ambiente físico da escola, higienização e merenda. O Quadro 1 redimensiona e dá voz aos sujeitos sobre alguns dos aspectos destacados acima.

Quadro 1 - Visões dos discentes para melhoria da qualidade da educação da EJA

\begin{tabular}{|l|c|c|c|}
\hline \multicolumn{1}{|c|}{ Categorias Educacionais } \\
\hline \multicolumn{1}{|c|}{ Sujeito } & Variável & Percentual & Quantidade \\
\hline Discentes & Aprendizagem & $47 \%$ & 82 \\
\hline Discentes & Material didático & $18 \%$ & 32 \\
\hline Discentes & Transporte & $14 \%$ & 24 \\
\hline Discentes & Merenda Escolar & $14 \%$ & 24 \\
\hline Discentes & Estrutura Física & $7 \%$ & 13 \\
\hline
\end{tabular}

Fonte: própria autoria (2020)

A categoria aprendizagem apresentou representatividade de $47 \%$ na fala dos entrevistados, a partir do questionamento relacionado às mudanças para que a qualidade seja 
um processo constante na EJA. Tal possibilidade expõe que esses sujeitos reconhecem que não são depósitos de conhecimentos descontextualizados, tendo a capacidade de compreender e construir significados a partir de sua aprendizagem. Nesse intuito, Freire (2007) entende que a prática, dita como educativa, deve ir além de onde se está, ou seja, ultrapassar as barreiras do dito, possibilitando intervenções e interconexões dos conhecimentos.

Os dados acerca das respostas do alunos dimensionaram na categoria "material didático (livros e atividades de ensino)" têm a expressividade de 18\%. Esse material afeta diretamente o ensino teórico e, em parte, não se alinha com o cotidiano. Relacionado a esse aspecto, Schmitz (1993) discorre que o material ou recurso didático é caracterizado como a ligação entre a palavra e a realidade a ser desvendada. O material didático pode, assim, substituir uma situação real que não pode ser vivenciada e, além disso, estabelece um vínculo fidedigno com a aprendizagem do aluno.

As falas dos sujeitos evidenciaram que o transporte teve a frequência de $14 \%$. Segundo os alunos, a condução sempre chega atrasada para transportá-los e há dias em que o transporte não circula. A LDB 9394/96 implementá que é dever do Estado a garantia do atendimento por meio de programas suplementares, sendo um deles o transporte escolar.

Quando analisadas as entrevistas, a categoria "merenda escolar" evidenciou o percentual de 14\%. Nos dizeres de Teixeira (2008), a alimentação escolar, além de servir para suprir aspectos fisiológicos, têm uma vinculação muito importante com os elementos socioculturais.

A categoria "estrutura física (melhoria)" apareceu em 7\% das falas. Relativo a esse aspecto, Satyro e Soares (2007) dispõem que a deficiência e falta de manutenção da estrutura física escolar influencia negativamente na qualidade da educação. A falta de biblioteca equipada com um bom acervo bibliográfico, laboratórios para execução de aulas práticas, salas com pouco espaço, são, dentre outros, aspectos que estão interligados à aprendizagem.

A partir das informações evidenciadas, é importante destacar que a categoria "aprendizagem" e a necessidade de geri-la é recorrente nas entrevistas semiestruturadas e nas conversas com os sujeitos da pesquisa. Nesse sentido, Amorim (2012) é incisivo em destacar que a escola precisa estar aberta ao dialógico, para a resolução das subjetividades que permeiam a contemporaneidade, ampliando os espaços democráticos e inovadores no ambiente escolar, a fim de suscitar o entendimento de que o ensino e a aprendizagem é, por natureza, o lugar no qual a complexidade do mundo social e produtivo está presente.

O posicionamento dos discentes caminha para a construção de ideias em que a concepção de gestão está atrelada à administração da escola; organização; responsabilidade; lida com as mais variáveis de comportamentos humanos; uma gestão diferenciada, pois requer 
sensibilidade por se tratar de um público diferenciado. Atrela-se também à gestão em EJA a permanência dos alunos em sala de aula e a possibilidade de preparação do sujeito para uma vida social atuante.

E, por outro lado, os docentes sugerem que se elabore uma proposta curricular voltada para a realidade do jovem adulto e do idoso, na qual suas experiências de vida sejam valorizadas, para que esses educandos tenham possibilidades de ultrapassar os conhecimentos construídos no senso comum para o conhecimento científico, e um currículo que valorize a multidisciplinaridade, bem como o desenvolvimento de projetos, abordando as questões de discriminação social, violência, desrespeito ao ser humano e desvalorização do professor.

Esses discentes (sujeitos) veem na escola a melhor forma de resgatar a sua dignidade, mas encontram empecilhos, mesmo sabendo que seus direitos têm sido negados, o que nos faz refletir por meio do currículo é resgatar a sua história de vida. Na maioria das vezes, o trabalho obriga o jovem adulto trabalhador a deixar a escola, mas o sistema capitalista exige formação e conhecimento necessário ou para buscar emprego ou até mesmo para permanecer nele.

A educação de jovens e adultos necessita avaliar sempre sua identidade, reelaborar os seus objetivos e conteúdos e explicitar seus currículos. Os debates precisam ser críticos, abertos à mudança, capazes de intervir em processos de produção cultural que tenham alcance político. É nesta direção de formação política para cidadania democrática que se deve caminhar na reelaboração de currículos de educação de jovens e adultos e na formação continuada aos profissionais que nela atuam. O Quadro 2 redimensiona e dá voz aos docentes sobre alguns dos aspectos já destacados.

Quadro 2 - Percepção dos docentes para melhoria da qualidade da educação da EJA para os discentes

\begin{tabular}{|l|c|c|c|}
\hline \multicolumn{1}{|c|}{ Categorias Educacionais } \\
\hline Sujeito & Variável & Percentual & Quantidade \\
\hline Docentes & Aprendizagem & $35 \%$ & 14 \\
\hline Docentes & Material didático & $15 \%$ & 1 \\
\hline Docentes & Transporte & $3 \%$ & 2 \\
\hline Docentes & Merenda Escolar & $5 \%$ & 1 \\
\hline Docentes & Estrutura Física & $2 \%$ & 16 \\
\hline Docentes & Evasão Escolar & $40 \%$ & 6 \\
\hline
\end{tabular}

Fonte: própria autoria (2020)

Entende-se, assim, que, para atingir o papel de intelectual crítico, o professor deve analisar sistematicamente sua situação profissional, os aspectos políticos, sociais, culturais e 
Seção: Gestão - Artigo original

econômicos que permeiam a escola e seus alunos, questionar seu próprio trabalho, suas concepções de escola, currículo, ensino, metodologias e assumir a responsabilidade da produção e utilização do conhecimento, firmando compromisso com a transformação do pensamento e da prática dominante da aprendizagem, conforme o enfoque dos $35 \%$. Na perspectiva de Giroux (1997), a reflexão amplia o horizonte, incluindo a compreensão da ação dos professores com a estrutura e o funcionamento institucional, exercendo sobre a prática de ensino sua prática, bem como o compromisso social, político e inserção do seu exercício profissional de docente.

A EJA fundamenta-se nas Diretrizes Curriculares Estaduais para a Educação de Jovens e Adultos em que se identificam os eixos cultura, trabalho e tempo como os que deverão articular toda a ação pedagógico-curricular nas escolas. Com isso, a troca de experiência permite a construção de novos saberes para seu desenvolvimento profissional. Dessa forma, a formação dos professores precisa "investir positivamente nos saberes de que o professor é portador, trabalhando-os de um ponto de vista teórico e conceptual" (NÓVOA, 1995, p. 27).

Enfim, a evasão escolar é fato que afeta a estrutura escolar, bem como dos fatores didáticos e pedagógicos que possivelmente estejam colaborando para a sua evasão. Sendo a evasão escolar um agravante social, visto que diversos os fatores contribuem para o índice evasivo escolar, é necessário que a instituição escolar busque resgatar o aluno que permanece à margem da sociedade e desenvolva estratégias que reduzam a evasão de alunos. De acordo com Gagno e Portela (2013), “A garantia de acesso e permanência com sucesso para estudantes de EJA deve ser o objetivo de toda a sociedade, e isso só será possível na medida em que as diferenças forem respeitadas", por isso é de suma importância a estratégia do professor diante do currículo selecionado, para que esse não seja permeado de ideologias sinalizadas e sim de pesquisas individuais que atendam aos interesses culturais e sociais dos discentes.

A concepção dos discentes está direcionada à ideia de que a gestão em EJA resume-se aos processos técnicos administrativos, não levando em conta as características que são específicas para o desenvolvimento do trabalho em EJA. Nesses moldes, Begot e Nascimento (2002) expõem que o gestor escolar da contemporaneidade tem que se ater à preocupação cotidiana no exercício da função que desempenha e da importância e responsabilidade colocada sobre si. É importante demarcar que o gestor que vislumbra sucesso na organização escolar deve ser maleável e se (re)formar cotidianamente para ser atuante frente às demandas globais.

Diante desse aspecto, a educação e os processos de aprendizagem devem colocar o sujeito diante de novos enfrentamentos para compreender o mundo e a si mesmo. É importante destacar que a aprendizagem dos sujeitos jovens e adultos é iniciada anteriormente aos processos de escolarização; portanto, esses sujeitos já tiveram contato com a língua falada e 
escrita, processos matemáticos através de cálculos simples e tantos outros conhecimentos.

Nesses moldes, esses são outros sujeitos que adentram a escola e, consequentemente, necessitam de outras pedagogias de aprendizagem.

A partir das informações coletadas, é importante destacar que a categoria aprendizagem e a necessidade de geri-la é recorrente nas entrevistas semiestruturadas e nas conversas com os sujeitos da pesquisa. Nesse sentido, Amorim (2012) é incisivo em destacar que a escola precisa estar aberta ao diálogo, para a resolução das subjetividades que permeiam a contemporaneidade, ampliando os espaços democráticos e inovadores no ambiente escolar, a fim de suscitar o entendimento de que o ensino-aprendizagem é, por natureza, o lugar no qual a complexidade do mundo social e produtivo está presente. Por isso, no Quadro 3, damos destaque às relações entre as entrevistas dos discentes e a percepção dos docentes na EJA.

Quadro 3 - Percepção dos docentes para melhoria da qualidade da educação da EJA para os discentes

\begin{tabular}{|c|c|}
\hline Visão dos discentes x Perceção dos docentes & Categorias \\
\hline $\begin{array}{l}\text { Os alunos precisam de estímulos para melhorarem o interesse pela aprendizagem, bem } \\
\text { como para dar continuidade aos/nos estudos, pois é gritante a evasão na escola. Há } \\
\text { também necessidade de acompanhamento da família e maior suporte pedagógico. }\end{array}$ & \multirow{5}{*}{ Aprendizagem } \\
\hline $\begin{array}{l}\text { Os aspectos a serem geridos na EJA para a melhoria da qualidade estão no oferecimento } \\
\text { de material didático de qualidade capacitado para atender aos anseios de aprendizagem, } \\
\text { pois que são alunos com pouco tempo dedicado aos estudos devido aos afazeres. }\end{array}$ & \\
\hline $\begin{array}{l}\text { Os assuntos devem buscar sempre lastrear-se ao cotidiano do educando, buscando } \\
\text { fortalecer sua autoestima e dar qualidade na construção do conhecimento. }\end{array}$ & \\
\hline $\begin{array}{l}\text { Conhecer a realidade do aluno, trabalhar de forma interdisciplinar, no que for proveitoso } \\
\text { para o aluno. }\end{array}$ & \\
\hline $\begin{array}{l}\text { As relações de ensino-aprendizagem na EJA, identificando características quanto a } \\
\text { metodologia, dificuldades e relações sociais nesse processo, para jovens e adultos que não } \\
\text { concluíram ou tiveram acesso à educação institucionalizada. }\end{array}$ & \\
\hline $\begin{array}{l}\text { Material didático compatível com a realidade do aluno, cursos de formação continuada aos } \\
\text { professores. }\end{array}$ & \multirow{3}{*}{$\begin{array}{l}\text { Material } \\
\text { didático }\end{array}$} \\
\hline $\begin{array}{c}\text { Quando eu explico um assunto, tenho sempre que copiar no quadro, porque os alunos não } \\
\text { têm por onde estudar. }\end{array}$ & \\
\hline Mais livros, mais aulas interessantes, uma estrutura física que acolha o estudante. & \\
\hline Transporte para chegar mais cedo na escola, reduzindo o atraso dos alunos nas aulas. & Transporte \\
\hline $\begin{array}{l}\text { Melhoria da água, merenda escolar, organização dos banheiros masculinos, e a disciplina } \\
\text { dos alunos em sala de aula. }\end{array}$ & $\begin{array}{l}\text { Merenda } \\
\text { escolar }\end{array}$ \\
\hline $\begin{array}{l}\text { Precisa melhorar a sala, são paredes que não pintaram, os banheiros não têm uma boa } \\
\text { higiene, para mim é uma das melhores escolas do município, mas algumas coisas precisam } \\
\text { melhorar, tipo o lazer na quadra, precisando de materiais e equipamentos de educação } \\
\text { física. }\end{array}$ & Estrutura física \\
\hline
\end{tabular}

Fonte: Elaboração do pesquisador, 2018. 
Seção: Gestão - Artigo original

Nesses moldes, Amorim et al (2009) pontuam que a organização escolar atual deve estar constituída a partir de exigências sociais e educacionais. Diante disso, a escola da contemporaneidade deve mobilizar e tornar reais recursos materiais e humanos para que o jovem encontre percursos pedagógicos que fortalecem e tornam concreto o processo de aprendizagem e a qualidade educacional.

É importante destacar que, visando à qualidade na EJA, a gestão escolar é percebida como sendo um dos elementos integradores entre os pares, capazes de movimentar, mobilizar, refletir, promover e tornar concreto processos educativos organizacionais que de fato atendam e sanem as demandas que são condições essenciais para a qualidade da educação na modalidade.

\section{CONCLUSÃO}

A partir da análise do contexto histórico, observa-se que a EJA vem se sobressaindo no cenário educacional, devido às mobilizações promovidas pela sociedade ao longo dos últimos anos, entretanto, muito ainda há de ser feito para reparar a exclusão a que foi submetida a população adulta. De certa forma, a pesquisa realizada atendeu ao que se propôs, pois possibilitou, por meio da pesquisa bibliográfica e da investigação do cotidiano escolar, conhecer o universo da EJA, um pouco mais de seus sujeitos e diagnosticar os principais impasses e desafios que são vivenciados pelos docentes.

A relação entre a Gestão Escolar e a EJA é um fato que merece um olhar minucioso, pois existem vários entraves que têm impossibilitado que ambas caminhem entrelaçadas nas instituições educacionais. São problemáticas que giram em torno de questões administrativas, financeiras e pedagógicas, que entravam o processo de gerir, e com qualidade, essa modalidade. É urgente e necessário refletir que a EJA foi e é ainda tratada (com poucas mudanças), através de campanhas e programas educacionais de pequena duração. Desse modo, essa modalidade de ensino, que sofre constantes modificações, devido aos programas de governos, não é encarada ainda como possibilidade de modificação social e ainda é extremamente estigmatizada.

$\mathrm{Na}$ instituição observada, constatou-se a necessidade de se adaptarem os documentos norteadores do trabalho pedagógico às especificidades do público a que atende, sendo necessário colocar em prática orientações voltadas exclusivamente para a EJA. Em relação aos impasses e desafios, dois aspectos se tornaram evidentes na visão dos professores: a falta de uma formação específica para o professor de EJA e a evasão, já que o número de alunos que se matricula no início do ano é bem elevado, porém, no decorrer do ano, o número de matrículas diminui. 
Seção: Gestão - Artigo original

Compreender a lógica de que a escola é uma instituição complexa, plural, heterogênea e cheia de subjetividades e pensar que as instituições de ensino que ofertam a modalidade da EJA são imensamente mais complexas, pelas trajetórias de vida cultural, social e econômica de seus sujeitos, instiga pressupostos organizacionais para que a gestão escolar se consolide como um campo de inovação.

Para esse fim, os encaminhamentos iniciais apontam para a necessidade de uma gestão democrática que avalie quais avanços e retrocessos estão atuando sobre a EJA no Centro Educacional de Tijucas e o que necessita de ser gerido, redimensionado e refletido. É importante demarcar a necessidade de maiores graus de autonomia e participação dos atores envolvidos, além da comunidade no entorno. É indispensável refletir acerca de uma possibilidade paradigmática que promova inovação e amplie os horizontes da instituição escolar. Esse redimensionamento da gestão escolar versa encontrar uma nova concepção de gestão que leve em conta os aspectos estruturantes da educação: a dialogicidade, o processo participativo, a criatividade e a diversidade cultural e pedagógica.

É necessário que o gestor crie um espaço inovador e favoreça a construção e a consolidação de novas teorias, de métodos e técnicas gestoras que deem um sentido contemporâneo à instituição escolar e ao processo formativo dos alunos. É necessário que o lugar da gestão em EJA seja um ambiente prazeroso e comprometido com um modelo de educação que tenha equidade e promova o espaço democrático, igualitário, possibilitando a criação de novos saberes educacionais, sociais e culturais.

Apesar de vários aspectos da EJA permanecerem em discussão, esta pesquisa também indicou a necessidade de proporcionar ações voltadas para a formação dos docentes que atuam nesta modalidade de ensino, o que deve constituir uma preocupação não apenas para as instâncias formadoras, mas também para os gestores públicos que estão à frente das redes de ensino. Não investir em uma formação docente específica e adequada para o educador de adultos contribui para tornar questionável a qualidade do ensino, dos materiais que vêm sendo oferecidos a este público e para colocar em dúvida o cumprimento de um direito prescrito em lei.

Diante desses direcionamentos, a gestão escolar que versa a inovação deve articular o processo de ensino aprendizagem, a gestão das atividades administrativas e financeiras da escola como sendo um todo complexo, contraditório, mas, único e estruturado, de modo a valorizar e desenvolver a visão de mundo do aluno, para que ele possa refazer os diferentes caminhos formativos, que precisa empreender, em sua jornada pedagógica, cultural e social.

\section{REFERÊNCIAS}


ALARCÃO, I. Professores reflexivos em uma escola reflexiva. 3. ed. São Paulo: Cortez, 2004.

AMORIM, A. Políticas públicas em educação, tecnologia e gestão do trabalho docente. Salvador: EDUNEB, 2012.

AMORIM, A. et al (org.). Educação e contemporaneidade: processos e metamorfoses. Rio de Janeiro: Editora Quartet, 2009.

ARROIO, M. Educação de jovens-adultos: um campo de direitos e de responsabilidade pública. In: SOARES, L.; GIOVANETTI, M. A. G.; LINO, N. (orgs.). Diálogos na educação de jovens e adultos. 2. ed. Belo Horizonte: Autêntica, 2005.

ARROYO, M. Outros sujeitos, outras pedagogias. Petrópolis, RJ: Vozes, 2012.

BARCELOS, V. Educação de Jovens e Adultos. Petrópolis. RJ: Vozes, 2010.

BARONE, R. R. M. Educação e políticas: questões para o debate. Boletim Técnico do SENAC, São Paulo, v. 26, n. 3, 2000.

BEGOT, M. G. S.; MARLENE, M. J. C. Gestão Escolar: numa perspectiva democrática. Monografia de Conclusão de Graduação. Centro de Ciências Humanas - Universidade da Amazônia. Belém, 2002.

BITTAR, M.; OLIVEIRA, J. Gestão e Políticas da Educação. Rio de Janeiro: DP\&A, 2004.

BRASIL. Lei 9394/96, Lei de Diretrizes e Bases da Educação Nacional. Disponível em: http://www.planalto.gov.br/ccivil_03/leis/L9394.htm. Acesso em: 3 jul. 2017.

CALHÁU, M. do S. M. Planejamento e avaliação. In: Salto para o futuro: Educação de jovens e adultos. Brasília, v. 10, p. 53-61, 1999.

CAVACO, M. H. Ofício de professor: o tempo e as mudanças. In: NÓVOA, A. (org.). Profissão professor. Porto: Porto Editora, 1992.

CONTRERAS, J. A autonomia de professores. São Paulo: Cortez, 2002.

DENZIN, N.K.; LINCOLN, Y.S. O planejamento da pesquisa qualitativa. Porto Alegre: Penso, 2006.

FERNANDES, M. E. Memória Camponesa. In: Anais da 21 ${ }^{\text {a }}$ Reunião Anual de Psicologia, SPRP, Ribeirão Preto, 1991.

FLICK, U. Introdução à pesquisa qualitativa. 3. ed. Porto Alegre: Artmed, 2009.

FREIRE, P. Educação como prática da liberdade. 16. ed. Rio de Janeiro: Paz e Terra, 2007.

FREITAS, K. S. de. Gestão da Educação: a formação em serviço como estratégia de melhoria da qualidade do desempenho escolar. In: CUNHA, M. C. (org.). Gestão Educacional nos Municípios. Salvador: EDUFBA, 2009.

FREIRE, P. Pedagogia da autonomia: saberes necessários à prática educativa. São Paulo: Paz e terra, 1996.

FUCK I. T. Alfabetização de adultos: relato de uma experiência construtivista. Petrópolis: Vozes, 1993.

GAGNO, R. R.; PORTELA, M. S. Gestão e Organização da Educação de Jovens e Adultos: Perspectiva de Prática Discente. São Paulo, 2003. 
GATTI, B. A construção da pesquisa em educação no Brasil. Brasília: Liber Livro Editora, 2012.

GIL, A. C. Métodos e técnicas de pesquisa social. 5. ed. São Paulo: Atlas, 1999.

GIL, A. C. Como elaborar projetos de pesquisa. 4. ed. São Paulo: Atlas, 2008.

GIROUX, H. A. Os professores como intelectuais: rumo a uma pedagogia crítica da aprendizagem. Porto Alegre: Artmed, 1997.

GOLDENBERG, M. A arte de pesquisar: como fazer pesquisa qualitativa em Ciências Sociais. Rio de Janeiro: Record, 1999.

KUHN, T. A estrutura das revoluções científicas. São Paulo: Perspectiva, 1982.

LEÃO, D. O. de. Docência e alfabetização na EJA: espaços e tempos de formação cotidiana. In: GUSTASACK, F.; VIEGAS, M. F.; BARCELOS, V. (Orgs). Educação de Jovens e Adultos: Saberes e Fazeres. Santa Cruz do Sul: EDUNISC, 2007.

LIMA, J. S.; SILVA, M. S.; SANTOS, C. L. N. dos. Gestão e qualidade na EJA: contribuições para pensar a escola de jovens e adultos. In: AMORIM, A. FERREIRA, M. da C. A.; ALVES, E. V. (Orgs.). Gestão escolar, políticas públicas, projeto pedagógico em Educação de Jovens e adultos: os caminhos transformadores da qualidade da escola pública da EJA. Salvador: EDUNEB, p. 69-81, 2015.

LUCK, H. Gestão educacional: uma questão paradigmática. 11.ed. Petrópolis: Vozes, 2014.

LUCK, H. Dimensões da Gestão Escolar e suas Competências. Curitiba: Positivo, 2008.

LUCK, H. Em Aberto. Brasília, v. 17, n. 72, p. 7-10, fev./jun. 2000.

MACHADO, M. M. A prática e a formação de professores na EJA: uma análise de dissertações e teses produzidas no período de 1986 a 1998. In: Reunião anual da ANPED, 23, Caxambu, 2000 .

MEYER, C. Educar para a diversidade e cidadania: construindo a Educação. São Paulo, 2008.

MINAYO, M. C. S. O desafio do conhecimento. Pesquisa qualitativa em saúde. 9 ed. São Paulo: Hucitec, 2006.

MOLL, J. EJA como política pública local: atores sociais e novas possibilidades educativas. Educação e Realidade. Porto Alegre, v. 01, n. 01, p. 09-24, jul/dez. 2004.

NÓVOA, A. (org.). Vidas de professores. Portugal: Porto, 1995.

OLIVEIRA, I. B. Reflexões acerca da organização curricular e das práticas pedagógicas na EJA. Educar, n. 29, p. 83-100, 2007.

SATYRO, N.; SOARES, S. A infraestrutura das escolas brasileiras de ensino fundamental: um estudo com base nos censos escolares de 1997 a 2005. Brasília: IPEA, 2007.

SCHMITZ, E. Fundamentos da Didática. 7. ed. São Leopoldo: UNISINOS, 1993.

SOARES, L.; GIOVANETTI, M.A.; GOMES, N. L. Diálogo na educação de jovens e adultos. Belo Horizonte: Autêntica, 2005.

TARDIF, M. Saberes docentes e formação profissional. 5. ed. Petrópolis: Vozes, 2005.

TRIVIÑOS, A. N. S. Introdução à pesquisa em ciências sociais: a pesquisa qualitativa em educação. São Paulo: Atlas, 1987. 